\title{
En los límites de la ciudad: El caso de la Cañada Real Galiana de Madrid
}

\section{In the city limits: The case study of Cañada Real Galiana in Madrid}

\section{Candela Morado Castresana *}

Fecha de superación del Tribunal Fin de Máster: 22.07.2016

Tutor: Javier Ruiz

\section{Resumen}

Con esta investigación pretendemos estudiar la formación de territorios fronterizos en tanto que límites físicos y simbólicos de las ciudades a través del análisis de un caso concreto: La Cañada Real Galiana, que ejemplifica el límite este-sur de la ciudad de Madrid, pero también el límite de lo urbano y lo civilizado con un espacio sin ley ni orden. Para ello, tomaremos en cuenta diferentes escalas, considerándolas como perspectivas de análisis: escala legal y morfo-tipológica, escala mediática y la escala del discurso encarnado. Analizar la articulación de estas tres dimensiones nos permitirá comprender cómo se conforman políticas públicas, planes urbanos o imaginarios colectivos, desvelando la Cañada Real como un objeto múltiple, complejo y controvertido.

\section{Palabras clave}

Ciudad informal, imaginarios colectivos, estigmatización territorial, desigualdad urbana.

\begin{abstract}
The aim of this research is to explore the formation of city border areas in terms of physical and symbolic boundaries through the specific case study of La Cañada Real Galiana. This territory exemplifies both the south-east limit of the city of Madrid and the frontiers between civilised urbanisation and a space with no law and order. In order to do so, this research analyses three different fields: legal and morphotypological issues, media representation, and discourse. Analysing the articulation of these three aspects permit the evaluation of how public politics, urban designs and the collective imaginary are conformed. Through this process, La Cañada Real is revealed as a multiple, complex and controversial object.
\end{abstract}

\section{Keywords}

Informal city, collective imaginary, territorial stigmatization, urban inequality.

- Candela Morado Castresana es alumna de postgrado del Departamento de Urbanística y Ordenación del Territorio de la Escuela Superior de Arquitectura. Universidad Politécnica de Madrid e investigadora en el CSIC, candela.morado@gmail.com 


\section{Introducción}

"Slum, semi-slum, and superslum... to this has come the evolution of cities."

Patrick Geddes ${ }^{1}$

¿Qué ocurre cuando lo urbano se disuelve y pierde su forma habitual, cuándo las relaciones sociales que propicia dejan de responder a los modelos urbanos habituales? La Cañada Real Galiana nos permite estudiar procesos de urbanización que quedan en los márgenes, en las "afueras" de las ciudades. Lo urbano se construye en relación con un "otro" que le permite dibujar sus límites mediante procesos de constitución de subjetividades frente aquello que Julia Kristeva (2006) denomina "lo abyecto". La ciudad no sólo requiere de esos márgenes, si no que éstos forman parte consustancial de ella: son sus vertederos, sus mercados negros, sus espacios de pobreza..., todos ellos conforman lo que podemos llamar su contra-modelo de referencia.

Con esta investigación pretendemos estudiar la formación de territorios fronterizos, reflexionar sobre los límites tanto físicos como simbólicos de las ciudades a través del estudio de un caso concreto: La Cañada Real Galiana, que ejemplifica el límite este-sur de la ciudad de Madrid con Coslada, Rivas y Getafe, pero también la contraposición de lo urbano y lo civilizado con un espacio sin ley ni orden. Para ello, tomaremos en cuenta diferentes escalas, considerando las diferentes perspectivas desde las que se mira y se vive un territorio concreto. La redacción de un periódico, el pleno de un ayuntamiento, el diseño de un plan urbano o la experiencia cotidiana que los vecinos, los voluntarios de ONGs o los políticos profesionales configuran realidades diferentes sobre qué es la Cañada Real y cómo esta se caracteriza. Estas perspectivas, por tanto convergen en un mosaico plural, controvertido y complejo orientado por sus intereses, sus condiciones materiales y sus diferentes trayectorias. La ciudad se emplaza precisamente entre estos límites complejos, difusos y fragmentarios. A partir de su análisis podremos interrogarnos sobre qué papel juega el territorio en los procesos de segregación y marginalización, cómo se conforman los imaginarios entorno a la Cañada Real, y cómo reconstruir epistemológicamente lo urbano sin posicionarnos en el centro, en lo instituido, en lo normativo, sino allí donde estos límites se desdibujan.

Nos proponemos descubrir esas relaciones complejas que surgen de la simultaneidad, de la coexistencia y copresencia de una serie de agentes y acontecimientos en un territorio concreto como es La Cañada Real Galiana en Madrid en torno a un periodo concreto desde principios del asentamiento (años 60) hasta la actualidad. La Cañada Real es un caso muy excepcional de asentamiento "informal" (el más grande de Europa), por sus peculiaridades jurídicas y territoriales, que ha adquirido una gran presencia mediática en los últimos años, convirtiéndose en una cuestión muy controvertida, donde se articulan una pluralidad de perspectivas y posiciones en torno a las posibles soluciones de un problema que es tan social, como ecológico y político.

La formulación de nuestra hipótesis de trabajo es la siguiente: "La Cañada Real Galeana no constituye un ente único y homogéneo, está compuesto por una suma heterogénea de territorios con características bien diferenciadas, que se disponen de forma lineal en el territorio generando un límite tanto físico como simbólico respecto de la ciudad próxima".

${ }^{1}$ Citado en Lewis Mumford, The City in History: Its Origins, Its Transformations, and Its Prospects, New York 1961, p. 464. 


\section{Perspectiva y orientación metodológica}

¿Cómo definir una mirada que habilite una sensibilidad hacia las subjetividades que se crean en los márgenes? Proponemos el desarrollo de una perspectiva multiescalar, que atienda a las diferentes "escalas" a través de las cuales se articulan los procesos en la Cañada Real, para descubrir las conexiones complejas que surgen entre los diferentes órdenes de análisis. Entendemos el concepto de "escala", inspirándonos en el trabajo Marilyn Strathern (1999) y Alberto Corsín (2005), en su doble dimensión. Primero, como escala de magnitud, esto quiere decir, atendiendo a lo micro y a lo macro, analizando desde el nivel de los actores y el sentido que le dan al territorio hasta un ámbito más global, pasando por la escala territorial. Segundo, como escala de orden de conocimiento, esto son las diferentes dimensiones de la realidad relacionadas con cuerpos disciplinares de conocimiento, en nuestro caso estudiaremos: el territorial, el jurídico, el mediático y el socio-hermenéutico (discursos encarnados por sujetos socialmente situados). La metodología de investigación propuesta, entonces, consta de tres partes o tres "escalas", desde los que pretendemos aproximarnos a una realidad compleja, difícil de narrar de manera lineal y desde una posición fija y unívoca.

Escala primera: Territorial y jurídica. En una primera parte llevaremos a cabo un análisis documental con el objetivo de estudiar y evaluar el marco jurídico (estatal y autonómico) en el que se inserta el asentamiento, atendiendo a su evolución en el tiempo. El objetivo de este análisis es contextualizar en espacio y tiempo el proceso de apropiación del territorio. También incluiremos un análisis del territorio para descubrir y entender los patrones de asentamiento así como su estructura y límites. Para este punto se realizaran análisis de fotografías aéreas y se completó la información con derivas en el lugar para recoger datos de uso del espacio, espacio representativos o de reunión. El objetivo es detectar diferentes áreas morfo-tipológicas atendiendo a su uso (residencial, industrial, mixto,...), composición tipológica, estado de las infraestructuras, tamaño medio de parcela, al estado de la edificación y distancias medias a transporte público o dotaciones (educativas y sanitarias).

Escala segunda: Mediática. En segundo lugar realizaremos un análisis de los mass media. Tomaremos como muestra todas las noticias publicadas entre los años 2001 y la actualidad en los dos periódicos de principal tirada en España: El Mundo y El País. Hemos tomado estos dos medios por considerar que son los más relevantes en la creación de opinión y también por facilidad de acceso ya que ambos cuentan con hemeroteca digital. Dividiremos nuestro análisis mediático en 4 puntos: relevancia del tema, temáticas que aborda, identificaciones y palabras recurrentes.

Escala tercera: Socio-hermenéutica. Utilizaremos el método socio-hermenéutico ${ }^{2}$ gracias al cual podremos analizar el sentido que le confieren diferentes sujetos a la realidad de la Cañada Real. Mediante esta perspectiva epistemológica, se plantea un acercamiento a los discursos y percepciones de los actores que proviene de la tradición interpretativa de las Ciencias Sociales. Se trata de un acercamiento que acoge la pluralidad de perspectivas que se dan en la encarnación de discursos y relatos por parte de diferentes actores (vecinos, miembros de asociaciones, vecinos de barrios contiguos e instituciones implicadas en la toma de decisiones). Para ello, realizaremos cinco entrevistas en profundidad semiestructuradas a vecinos y agentes implicados. Para recabar

\footnotetext{
2 Para el sociólogo Luis Enrique Alonso (1998:31) desde la perspectiva socio-hermenéutica "la interpretación no se plantea como un sistema hipotético deductivo que permite la verificación o falsación de un conjunto de categorías predeterminadas y codificables, (excluyendo como "ruido" todo lo que no se adapta al modelo de validación), sino como un proceso de captación de productos discursivos reales para tratar de determinar, en ellos, el sentido real de la acción de los sujetos como sujetos sociales.".
} 
la información referente al discurso institucional, por dificultades en el contacto con agentes políticos o de la administración, decidimos analizar las actas de los plenos de los tres ayuntamientos implicados: Coslada, Madrid y Rivas. Por último, y para completar la información de nuestros informantes, hemos realizado una deriva por la Cañada Real para recoger posibles muestras de conflicto como los grafitis o carteles en el barrio ${ }^{3}$.

\section{Resultados}

La Cañada Real Galiana es una de las vías pecuarias más importantes de la península ${ }^{4}$, desde el S.XIII funciona como camino de trashumancia y corredor verde. Desde las primeras construcciones que se señalan en los años 60 (Franchini, 1988), el asentamiento ha ido creciendo durante 40 años ante la pasividad aparente de las administraciones y con prácticamente ninguna repercusión mediática.

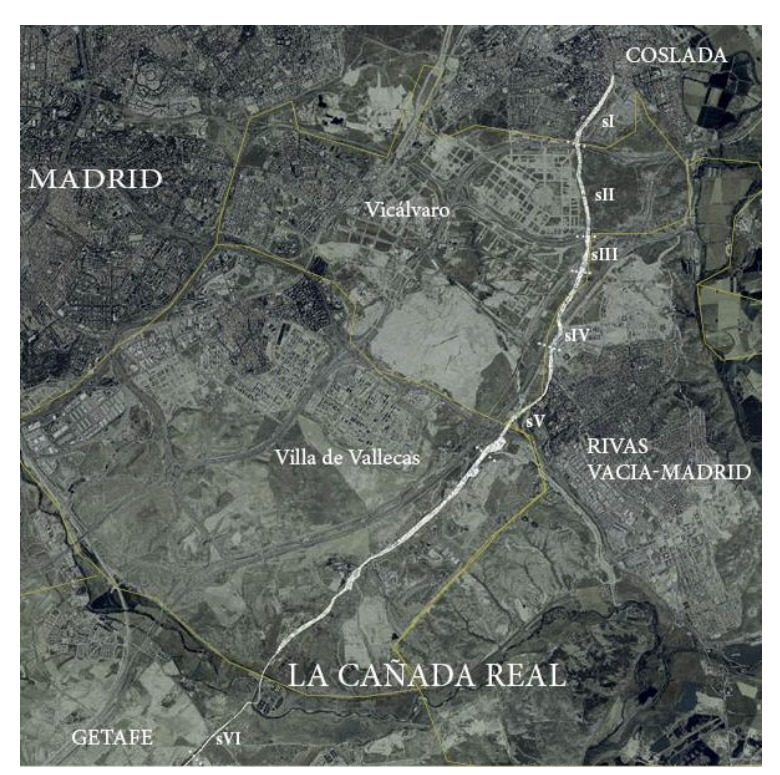

Ilustración 1. Imagen de los $15 \mathrm{Km}$ desde Coslada a Getafe. Fuente: Elaboración propia a partir de imagen GoogleEarth.
El tramo de Cañada que va a ser objeto de esta investigación conforma actualmente una gran huella constante y uniforme de $15 \mathrm{Km}$ desde Coslada hasta Getafe, territorio en el que viven más de 10 mil habitantes ${ }^{5}$. La Cañada se organiza en seis sectores que se corresponden con los diferentes tramos creados por la división que generan las grandes vías de comunicación M-45, R-3, M-50 y A-3 que la atraviesan.

Podemos resumir en tres los condicionantes que hacen de la Cañada un caso muy particular y que impulsaron la consolidación de este gran asentamiento informal. En primer lugar, el declive de la actividad trashumante. Con la falta de uso se fueron creando huertos y de este modo las casas de aperos fueron consolidándose como viviendas temporales. En segundo lugar, el problema habitacional que sufrió Madrid.

Primero con las familias que llegaban del campo a la capital (años setenta) y más tarde con la inmigración y desmantelamiento de asentamientos cercanos (años 2000), estas llegadas masivas de población hizo que se fueran consolidado viviendas de uso permanente. Cabe destacar que personas también vieron en este proceso una oportunidad para hacerse una segunda vivienda en el territorio de Cañada. Por último, su calidad como suelo demanial. La vías pecuarias son bienes de dominio público y por tanto "inalienables, imprescriptibles e inembargables", lo que significa que no se pueden ocupar, vender, regalar, ni están sujetas a normas de usucapión, de prescripción

\footnotetext{
3 Por cuestiones de seguridad, la deriva la hemos realizado sólo en los tramos correspondientes a los Sectores I, II, III, IV y V, eliminando el sector VI de nuestro recorrido.

4 Vías de comunicación que sirven para el tránsito de ganado de unas tierras a otras de la Península para buscar los pastos de temporada. Desde el s. XIII La Cañada Real fue empleada como vía para la actividad ganadera y el comercio lanar. Constituye una de las nueve grandes Cañadas Reales que recorren la Península de norte a sur y que se integran la Red Nacional de Vías Pecuarias.

5 No hay consenso sobre la cifra exacta de habitantes. El censo cifra en 8.000 los vecinos registrados, presumiblemente esta cifra sea bastante superior si sumamos los vecinos no registrados. El informe de Secretariado Gitano, 2011 da la cifra de 10.000, pero Wikipedia y algunos medios como ABC (2011) publican cifras en torno a los 40.000 ha.
} 
de los derechos de propiedad de los bienes pasados 30 años de uso ajeno (Fariña, 2009). Esta calidad del suelo, unida a 40 años de pasividad de las Administraciones en este territorio, ha favorecido la apropiación de un suelo que era "de todos" sin que nadie se opusiera.

\section{Escala primera: la Cañada Real Galiana desde el territorio y el marco legal}

\section{Marco legal y su evolución}

La parcelación en Cañada comienza en los años 60. Gracias a la información recopilada por Franchini sabemos que en el 1975 el desarrollo aún era leve y tan sólo alcanzaba el límite municipal entre Coslada y Madrid, pero en el 1991 las parcelaciones llegaban a ocupar la extensión actual, hasta la zona sur colindando con Getafe (Franchini, 1988). Durante la década de los 90 y durante los primeros años 2000 se intensifica la ocupación y la construcción de edificaciones, aumentando la densidad y el uso residencial permanente (Secretariado Gitano, 2011). Fue entonces cuando se aprueba una legislación específica que rige las vías pecuarias (estatal: Ley 3/1995, de 23 de marzo; autonómica: Ley 8/1998, 15 junio) estableciendo las bases para que las comunidades autónomas defiendan su integridad, protección y conservación. Garantizando el uso público de esta red de caminos tanto para facilitar el tránsito ganadero como para otros usos compatibles o complementarios (senderismo, cicloturismo, rutas a caballo, etc.).

En el año 2011 se aprueba la ley 2/2011, de 15 de marzo, ya que, a pesar de reconocer que la Cañada Real Galiana forma parte del "valioso patrimonio común", las vías pecuarias han sufrido un fuerte declive que ha propiciado intrusismo agrícola, residencial e industrial. Mediante la ley se desafecta íntegramente el tramo de Cañada que nos ocupa. Como consecuencia, los bienes de dominio público pasaron a tener la condición de bienes patrimoniales y de esta forma la Comunidad Autónoma podrá disponer de ellos para enajenarlos, cederlos, permutarlos o cualquier otro negocio jurídico permitido por la Ley 3/2001, de 21 de junio, de Patrimonio de la Comunidad de Madrid.

Tras el proceso de desafección y pasados tres años de desencuentros entre las administraciones, finalmente en el mes de abril del año 2014, se crea un Acuerdo Marco entre la Comunidad de Madrid, el Ayuntamiento de Madrid, el Ayuntamiento de Coslada y el Ayuntamiento de Rivas Vaciamadrid y la Delegación de Gobierno de Madrid. Con este documento se pretende acordar una serie de objetivos comunes en las materias de seguridad, urbanismo, vivienda, social y jurídico-civil, con los que resolver de forma definitiva los conflictos existentes en la Cañada Real Galiana. Mediante mesas compuestas por vecinos, técnicos y especialistas se pretende llegar a soluciones de consenso. El acuerdo finalmente lo firman todos los ayuntamientos menos el de Rivas Vaciamadrid. A día de hoy, el proceso no termina de tomar impulso y las convocatorias de las mesas son muy escasas o inexistentes, por lo que dos años después se continua sin ofrecer una solución a la problemática. 


\section{Morfo-tipología}

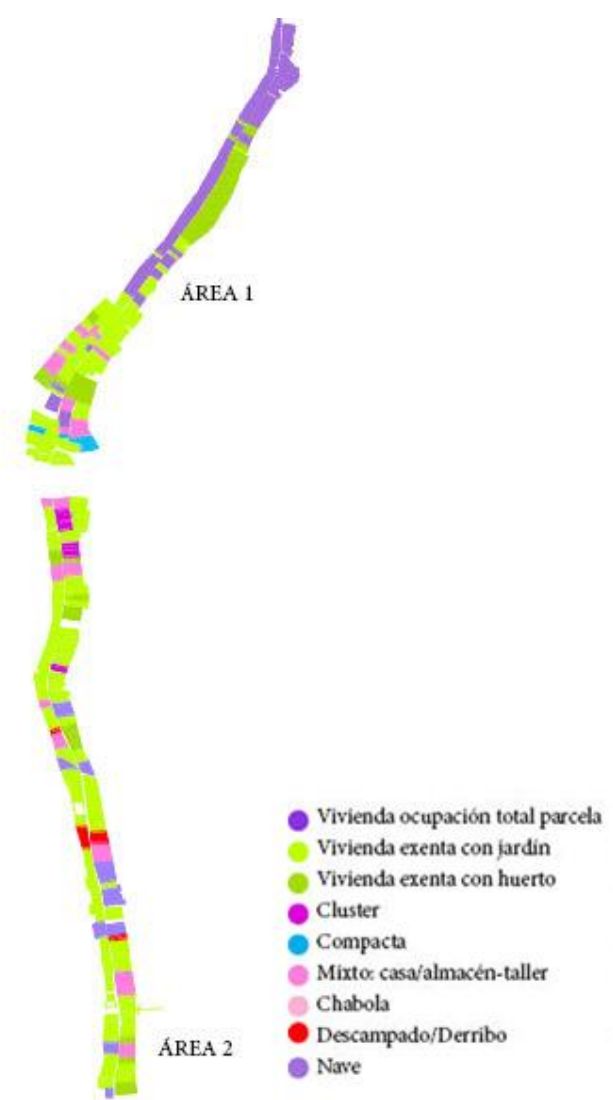

Áreas 1 y 2. Básicamente residenciales, con un tejido de unifamiliares con huerto o jardín, disfrutan de servicios mínimos autogestionados de asfaltado de la vía, alumbrado, alcantarillado, y se encuentran integradas en la trama de Coslada por lo que disfrutan de los servicios de los que esta dispone como autobuses urbanos y servicio de metro y cercanías. En el tramo colindante a Coslada (zona más norte) observamos una parcelación muy estrecha, respetando el ancho constante pero con muy poca superficie de fachada, esta tendencia va cambiando a medida que vamos bajando hacia el sur, donde las parcelas crecen de tamaño ampliando la superficie de fachada a la calle. Por lo general se tratan de viviendas de alta calidad muy parecidas a las de sus vecinos "legales", que sirven de escenario a prácticas sociales también muy similares, así, se puede observar personas socializado en la puerta de sus casas (mujeres mayores), compras en establecimientos, actividades de juego o paseos.

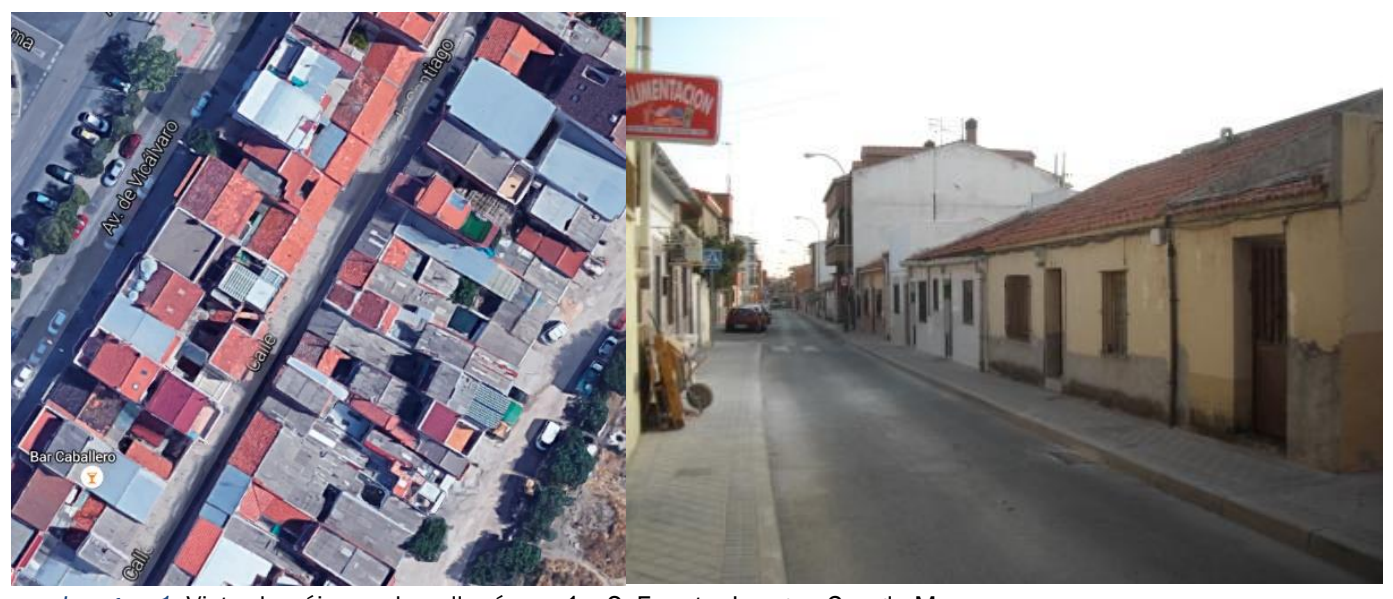

Imagen 1. Vista de pájaro y de calle, áreas 1 y 2. Fuente: Imagen Google Maps. 


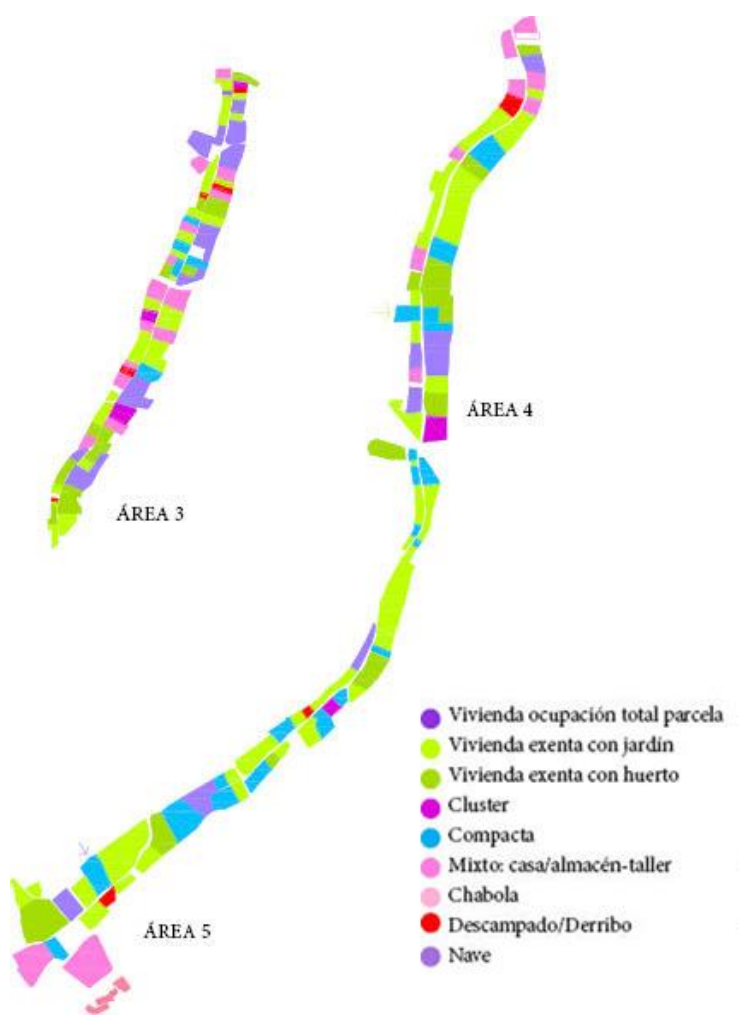

Gráfico 2. Ảreas morfo-tipológicas 3, 4 y 5.
Áreas 3, 4 y 5. Estas áreas tienen una trama más variada que intercala tejido residencial con tejido industrial de pequeña escala: naves industriales de almacenaje de material o de transportes. El tejido residencial presenta gran variedad de agrupaciones. La vía en estas áreas se encuentra en mal estado, no está asfaltada por lo que la formación de socavones y charcos es constante, además las construcciones son muy poco permeables: grandes vallas metálicas o de obra custodian ambos lados de la vía para dar paso a las viviendas, lo que crea un espacio público muy pobre y se reducen las interacciones. No hemos identificado ningún espacio de reunión más que un parque realizado por Todo Por la Praxis y Arquitectos sin Fronteras en 2011 y una mezquita musulmana ambos en el área 5. Respecto al tejido residencial, encontramos en la zona norte gran cantidad de vivienda unifamiliar con jardín o huerto. En la zona sur encontramos dos tejidos tipo de agrupación de viviendas. Un primer tipo que hemos denominado "cluster", compuesto por varias casas en torno a un espacio

central de lo que se infiere que en esas zonas hay clanes o familias que conviven y comparten solar. Y un segundo tipo "compacto" formado por construcciones dos alturas que colonizan el perímetro y colmatan la parcela dejando patios interiores, son fácilmente reconocibles porque tienen la cubierta plana con grandes azoteas repletas de antenas parabólicas.

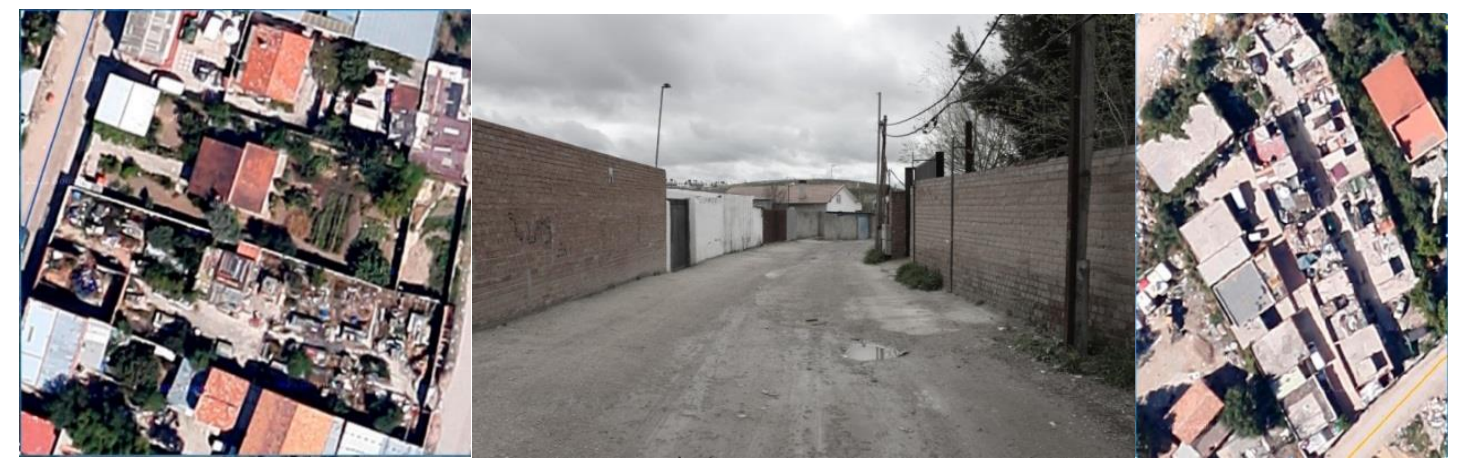

Imagen 2. Tejido tipo unifamiliar con huerto, vista de calle tipo y tejido compacto, áreas 3, 4 y 5. Fuente: Imagen GoogleMaps. 
Áreas 6 y 7. Las áreas 6 y 7 son las que se desarrollan más al sur del asentamiento y se tratan de zonas muy desconectadas del resto de áreas y de otras localidades.

Pobladas como hemos visto desde finales de los años 90 y más intensamente principios del 2000, recogieron la llegada de inmigrantes y habitantes de otros asentamientos desmantelados. Se suelen asociar con la existencias de algunas actividades "molestas, nocivas y peligrosas" (Cabrerizo, Rodríguez, 2014:10). Esta parte de la Cañada se ha ido convirtiendo en el "vertedero de Madrid", no sólo por alojar el complejo Valdemingómez, si no por concentrar también varias canteras, depuradoras de aguas y el "gran hipermercado de la droga" (ABC, 2013). Observamos una variedad muy grande de calidades, desde agrupaciones de tipo "cluster" y viviendas unifamiliares de altísima calidad con piscina, junto a escombreras y viviendas de tipo "chabola" de muy bajas calidades situadas en la zona sur.

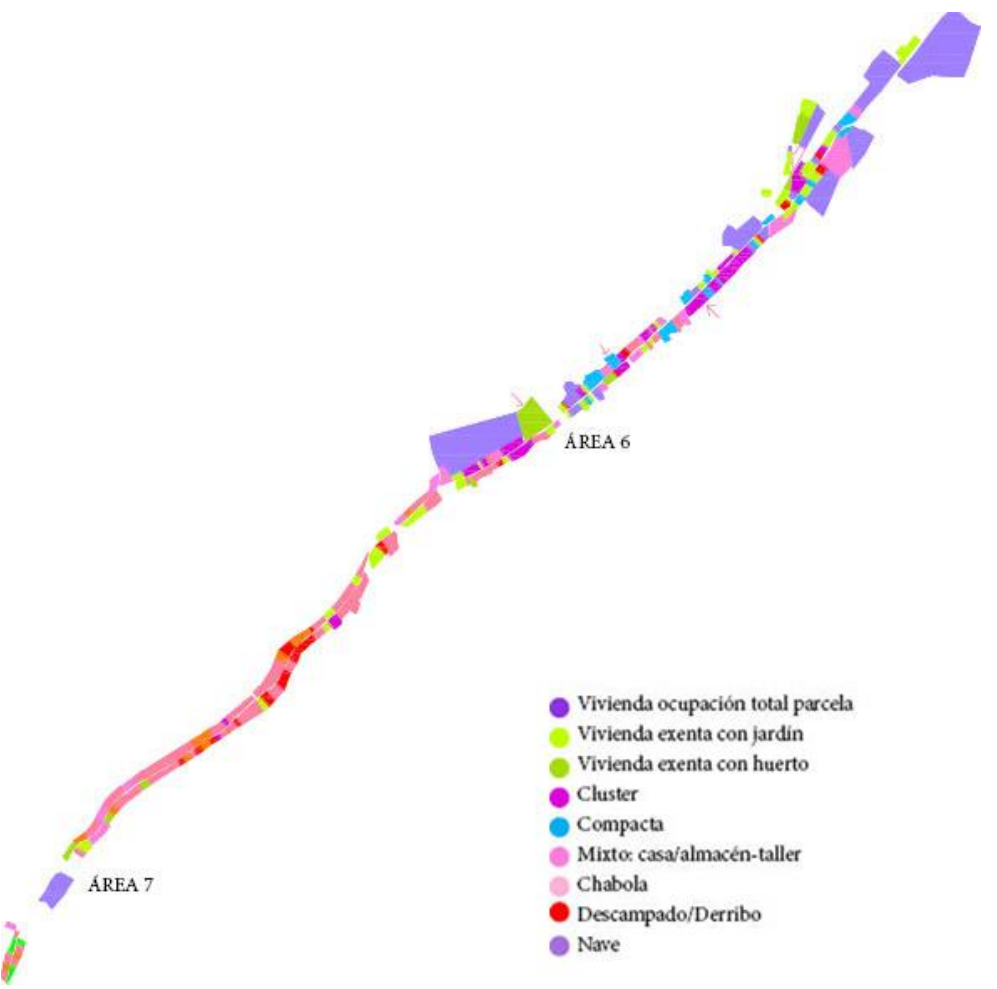

Gráfico 3. Áreas morfo-tipológicas 6 y 7.

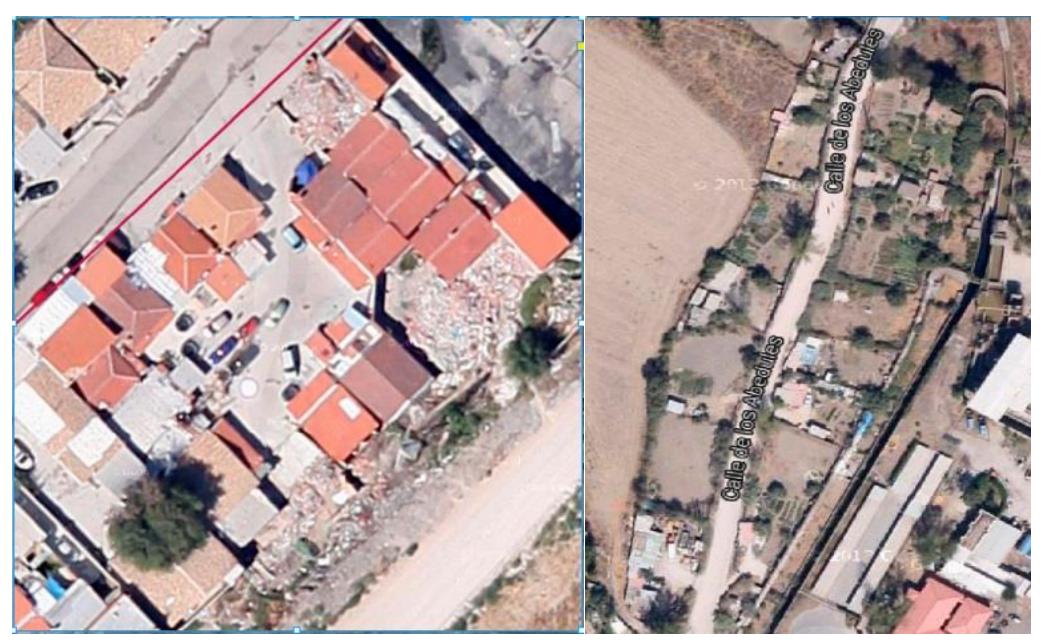

Imagen 3.Tejido tipo “cluster” y tejido tipo “chabola”. Fuente: Imagen Google Maps. 


\section{Transformaciones y presiones en los bordes}

La huella constante y regular que contiene a La Cañada Real queda rota bruscamente por las grandes vías de alta velocidad: M-45, R-3, M-50 y A-3, que no solo fragmentan la vía principal si no que suponen grandes barreras. Por lo que el paisaje de continuidad ahora resulta fragmentado, se crea una desconexión entre las partes, las vías constituyen barrera y generan zonas de peligro, ruido y contaminación. Pero a pesar de estar atravesada con vías de comunicación, La Cañada tiene unos accesos a infraestructura de transporte público muy deficientes. Sólo aquellas zonas cercanas a núcleos consolidados como Coslada o Rivas Vaciamadrid disponen de autobuses urbanos y servicio de metro. La dificultad de comunicación con la ciudad próxima condiciona e incluso limita las posibilidades de vida de la población, su desarrollo de actividades diarias y sus relaciones. (Díez et al, 2011:117).

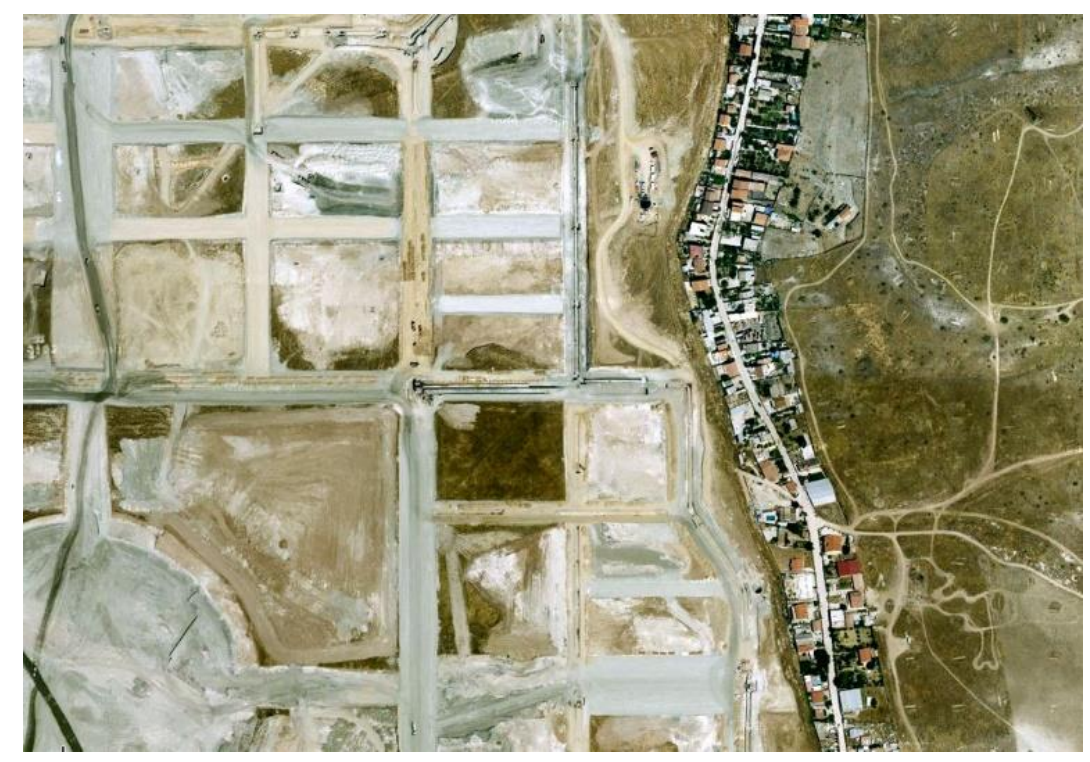

Imagen 4. Contacto del nuevo desarrollo urbano de los Berrocales y la Cañada Real. Fuente: Imagen GoogleMaps.

También por las características de su huella extensa en sus $15 \mathrm{~km}$ de longitud limita con Coslada, los desarrollos urbanísticos en marcha (Los Cerros, Los Ahijones, Los Berrocales, El Cañaveral, Valdecarros que sumarán más de 100mil viviendas de nueva planta), Villa de Vallecas y el municipio de Rivas-Vaciamadrid. Salvo el contacto con Coslada, donde el tejido de la cañada se inserta en el tejido urbano consolidado del municipio sin generar disonancias, el resto de los contactos resultan muy problemáticos. Son múltiples los intentos de los vecinos de Cañada de crear accesos a las zonas asfaltadas, y también constantes los bloqueos de esas salidas con bloques de hormigón o bolardos.

Como vemos, la Cañada es muy diversa y las siete áreas detectadas conforman realidades muy distintas con resultados dispares respecto a la ocupación o a la distribución espacial y grado de ocupación de los solares, a la diversidad en la intensidad de uso por parcela y de variación de características y calidades en la edificación. Además los constantes cortes con autovías, la escasa presencia de transporte público, el bloqueo de las posibles conexiones con los barrios próximos mediante bolardos o bloques de hormigón, construyen una frontera física que aísla y limita la capacidad de movimiento de los habitantes de Cañada, quedándoles como única alternativa de tránsito la vía central, a menudo embarrada, que atraviesa como una espina dorsal la Cañada. La Cañada además es un territorio frontera no sólo por su fragmentación y desconexión, sino que 
también su estructura lineal extensa lo lleva a ser un asentamiento en continua frontera física respecto a la ciudad próxima. 


\section{Escala segunda: la Cañada Real Galiana desde los mass media}

\section{Oportunidad de la noticia}

Muy pocas noticias sobre la Cañada Real fueron publicadas en El País o en El Mundo antes de 2006. Pese a ser un asentamiento que se establece en los años 60, no parece tener importancia para los medios, tan solo media docena de noticias al año nos hablan de la problemática que se sufre en este territorio. Sin embargo observamos con claridad como del año 2006 al año 2007 esta tendencia cambia y las noticias sobre La Cañada se multiplican hasta casi ocho veces. En 2007 hay 39 noticias y en 2011 tiene su pico superior con casi 60 noticias, esto supone más de una noticia por semana durante ese año. ¿Qué ocurre en Cañada en esos años 2006-2007? ¿Por qué empieza a ser noticia?

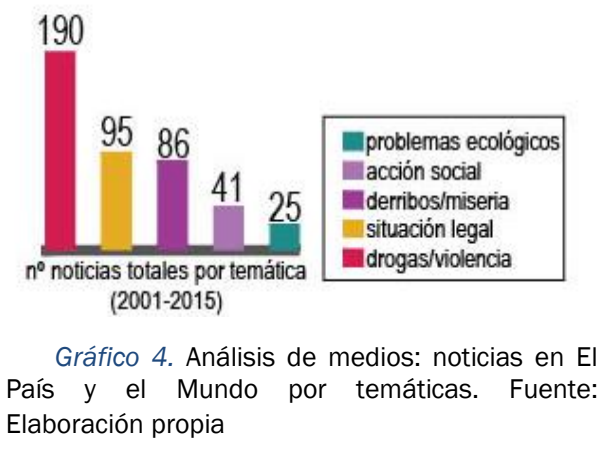

Fuente: Elaboración propia
También es notable la clara mayoría de artículos publicados en estos años en relación a la Cañada Real cuyo tema central son las drogas o la delincuencia y violencia. Del total de 437 noticias analizadas entre los años 2001-2015, 190 noticias tienen como tema central las drogas o la violencia, 95 se centran en la situación legal del asentamiento, 86 en noticias sobre los derribos de construcciones y en un porcentaje ya muy inferior noticias de acción social (41 noticias) y problemas ecológicos (25 noticias). Se presenta una imagen negativa del territorio asociada a actividades ilegales, peligrosas 0 nocivas.

\section{Elementos clave del relato mediático}

En el gráfico que se incluye a continuación (gráfico 5) hemos condensado la información de un modo visual y diagramático que nos facilitase la comparación y el análisis de los datos. En la parte inferior del gráfico encontramos las 437 noticias dispuestas en una línea del tiempo lo que nos permite saber cuántas noticias se publicaron cada año. En un segundo nivel podemos encontrar una recopilación de imágenes que ilustran las noticias. El tercer y cuarto nivel lo hemos elaborado con 220 noticias (la mitad de las noticias totales escogidas de manera aleatoria por año) un análisis más pormenorizado del cuerpo de los artículos. En el nivel "Identificación: La Cañada es..." hemos recopilado las diferentes asociaciones y definiciones que se han asociado a las palabras más recurrentes en el nivel superior.

Los medios tienden a presentarnos una Cañada con una realidad más o menos homogénea, chabolista y criminalizada. Esto queda demostrado por la reiteración que encontramos en los titulares y encabezados de las noticias de palabras como "droga", "miseria", "chabolas", derribos" y "basura". Si analizamos más detenidamente el cuerpo de los artículos encontramos múltiples identificaciones de Cañada con "ciudad fantasma", "foco contaminante", "vertedero", "poblado chabolista", "ciudad sin ley", "ciudad prohibida", "conflicto enquistado", "problema histórico", "caos", "zona de guerra" o "espacio en estado de sitio y excepción". Además es constante la alusión a sectores muy concretos de la población "clanes gitanos", "inmigrantes" y "toxicómanos", propiciando un imaginario común en torno a los agentes presentes en Cañada en los lectores de estos medios: "Son nómadas entre deposiciones, basura, ratas, serpientes y una violencia enorme" (El Mundo, 2014) o "Niños que juegan entre ratas, van sucios al colegio y apenas se integran" (El País, 2009). 


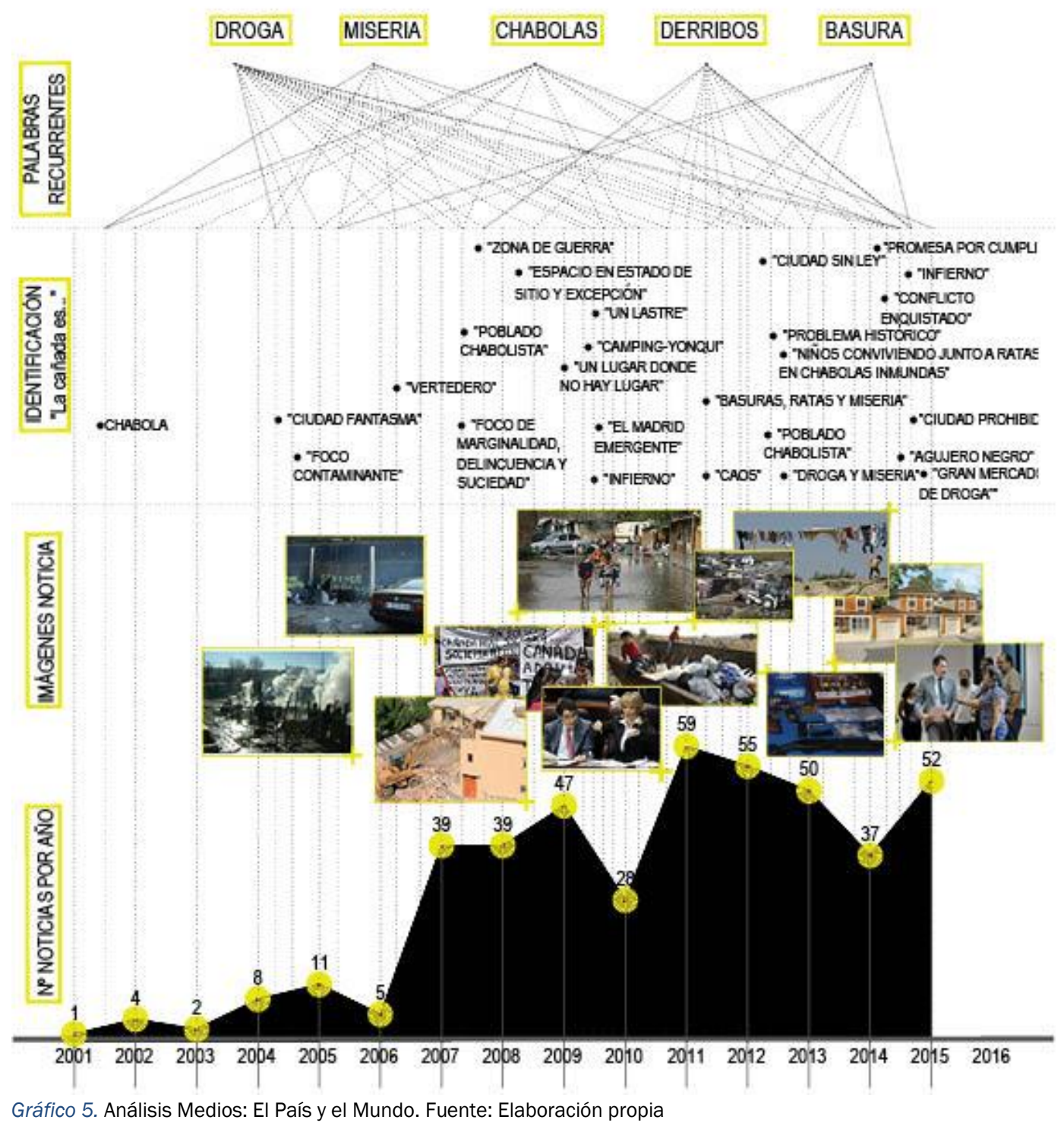

Observando las imágenes que acompañan a las noticias nos encontramos una amplia colección de imágenes de archivo de la policía con droga incautada, chabolas, imágenes de derribos de vivienda, imágenes de niños jugando entre basura y de políticos en sus despachos anunciando nuevas medidas o actuaciones en el territorio de Cañada. Estas imágenes refuerzan esa idea estereotipada de "ciudad sin ley" y "asentamiento marginal". Según una noticia de El País publicada en el año 2009 Esperanza Aguirre ponía en marcha la desafección de la Cañada Real argumentando: "Una Comunidad "de vanguardia" como Madrid que es "la número uno de España económicamente y una de las primeras de Europa" no podía permitirse un "lastre" como, en su opinión, ha sido desde hace años la Cañada Real para la región" (El País, 2009).

\section{Los roles de los agentes en las noticias}

Los actores que aparecen principalmente en las noticias analizadas como sujetos de acción son miembros de la policía, políticos (sobre todo E. Aguirre, A. Ruíz-Gallardón y A. Botella), miembros de la administración, drogadictos y traficantes. No son muchas las ocasiones en las que se citan a los habitantes de Cañada como actores o sujetos políticos con capacidad de agencia, que realicen actividades diferentes de las criminales. Los vecinos aparecen con roles pasivos sobre los que 
recae la acción y pocas veces como sujetos con posibilidades para agenciar sus propios procesos y aportar al barrio desde la participación y la política, para decidir sobre sus futuros posibles. Sólo en 42 del total de 437 noticias analizadas aparecen los vecinos de manera activa, reclamando derechos mediante asociaciones de barrio y colectivos como Asamblea Cañada Real, Plataforma Stop Derribos o Movimiento 15M.

¿Qué nos cuentan los medios y qué nos ocultan? El análisis de prensa nos presenta una Cañada homogénea, con una realidad de miseria y de delincuencia. Como afirman Wacquant y otros (2014: 236), "la estigmatización territorial no es una condición estática o un proceso neutral, sino una forma significativa y perjudicial de acción, mediante la representación colectiva, atada a un lugar determinado". El estigma se construye como una diferenciación basada en el desprestigio que surge de la mirada común de otros producida, diseminada y afianzada en el campo del poder, desde un lugar de autoridad capaz de fijar la representación (en este caso desde los medios, la administración y los políticos). De este modo se construye un "otro", alejado de la posición desde la que se enuncia, algo anormal, extraordinario, inmoral. Una lejanía que armoniza con el aislamiento real que tiene la Cañada, su inaccesibilidad material armoniza con su inaccesibilidad simbólica, como un objeto que infunde miedo y ante el que hay que estar vigilante y apartado. Por otra parte, el carácter problemático del territorio exige, dentro del relato, una transformación, es decir, como espacio sin ley y caótico debe de ser ordenado desde las instancias policiales y políticas. Esto refuerza la distinción que hemos visto entre los políticos y la administración como agentes activos y los habitantes de la Cañada como agentes pasivos, sin agencia.

\section{Escala tercera: la Cañada Real Galiana desde el discurso encarnado}

\section{Motivación del asentamiento y características de las viviendas}

El primero de nuestros informantes, JK. vecino de Cañada sector I-II, nació en uno de los bloques de Ciudad 70 propiedad de su abuela, pero desde muy pequeño (hace más de 25 años) se trasladó con su madre a la Cañada Real. JK. relata cómo las construcciones son "viviendas incrementales" que con el tiempo, a medida que se van obteniendo los recursos, se van completando según las necesidades. JK, al igual que otros informantes entrevistados, relata su infancia en la Cañada Real asimilándola a un pueblo, donde todos los vecinos se conocen y se ayudan con las construcciones y las instalaciones de las viviendas. Las viviendas son todas autoconstruidas por los propios vecinos ya que la mayor parte de ellos se dedican al negocio de la construcción. La instalación de electricidad y de agua en las viviendas se realiza mediante "pinchadas" a la red pública, práctica que ha sido objeto de múltiples conflictos con los vecinos de los barrios cercanos, quienes más de una vez les han cortado el suministro o bloqueado con hormigón las tuberías, dejándoles durante días sin abastecimiento. "Aquí todos queremos pagar, pero no nos dejan, es muy injusto, pero necesitamos el agua para vivir, por eso la pinchamos" (Informante H., vecino sector V). Respecto a la red de saneamiento, H. nos cuenta que muchos vecinos utilizan letrinas, "como se hacía antiguamente en los pueblos", y otros vecinos vierten mediante tuberías autoconstruidas las aguas negras a un arroyo cercano, pese a los problemas de salubridad que puede estar ocasionando en la zona.

\section{Vida cotidiana, espacios comunes y convivencia}

En nuestra deriva por el barrio de Cañada Real nos llama la atención la práctica inexistencia de espacios de encuentro o de reunión donde los vecinos puedan encontrarse. Vemos a niños jugando en los solares cubiertos de maleza o con escombros de antiguos derribos. Los vecinos señalan la total inexistencia de equipamiento público para los más de 8.000 vecinos que viven en Cañada Real, donde la población infantil representa un gran porcentaje de los habitantes (según el censo de 2011 de la Comunidad de Madrid, más de un 38\% de los habitantes de Cañada son menores de 
15 años). También señalan cierta sensación de inseguridad y reclutamiento de las actividades cotidianas hacia el interior de las parcelas.

Salvo en los sectores I y II, la vía no está asfaltada y son continuos los charcos y los baches, esto hace muy complicado el desplazamiento. "Cuando no llueve, se levanta muchísimo polvo, se respira el polvo, se te ensucia la ropa... Todo. Es una sensación muy desagradable y agobiante. $Y$ cuando llueve, toda la calle se embarra, se hacen charcos enormes. Es muy complicado circular por ahí. Y claro, te deja completamente incomunicado. Esto es un problema para los niños con el acceso al cole. Muchos viven lejos de donde les recoge la ruta escolar y no pueden llegar con el coche" (Informante R., psicóloga social). La incomunicación nos remite a una realidad rural, donde la vida se desarrolla alejada de los centros urbanos y de sus servicios o equipamientos. Pero además, la presencia del barrio señala e identifica a los vecinos de Cañada. "También pasa mucho que llegan llenitos de barro a clase (...) y en el centro educativo, los profesores, muchas veces no lo entienden. No es que salgan sucios de casa, es que es imposible mantenerse limpio. El barro es un distintivo de Cañada. Nosotros siempre bromeamos con eso cuando nos manchamos las botas de barro, pero para los niños no es fácil, genera mucho estigma" (Informante R., psicóloga social).

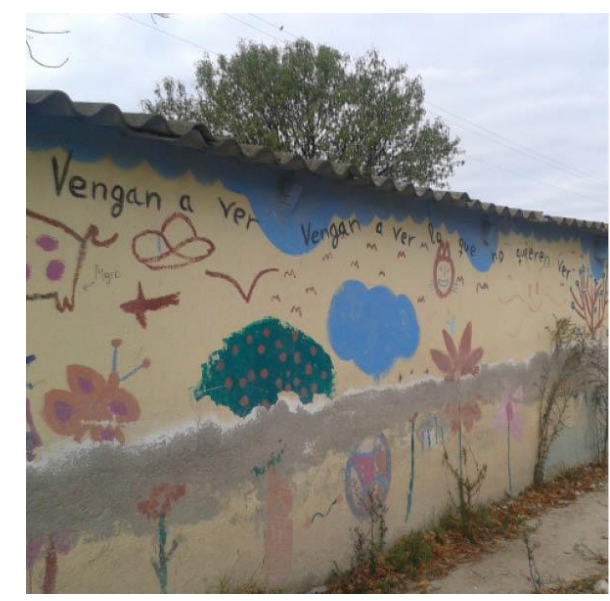

Imagen 5. Graffiti sector $V$ donde puede leerse: "Vengan a ver, vengan a ver lo que no quieren ver". Fuente: Elaboración propia
Estas situaciones de conflicto generan no sólo una frontera física, sino que también están construyendo una frontera simbólica entre los dos mundos el legal y el ilegal, estigmatizando a los vecinos de Cañada. En la entrevista a nuestra quinta informante, A. vecina de Rivas Vacía Madrid, nos contaba que nunca había ido a Cañada pese a estar a $5 \mathrm{~min}$ de su casa, "¿qué se me ha perdido a mi ahí? Una vez me confundí en un desvío con el coche y casi me meto de lleno en la Cañada, pasé mucho miedo... (...) No conozco a nadie de ese barrio, pero una amiga mía sí, su hermano iba al colegio con un gitano de la Cañada y siempre daba muchos problemas, llegaba muy sucio a clase" (Informante A.). En esta entrevista dimos cuenta del imaginario construido sobre Cañada como un espacio peligroso, sucio que no se debe visitar.

\section{Perspectivas de futuro}

Las amenazas de derribos son constantes en el barrio de Cañada Real, no sólo forma parte de muchos de los grafitis que nos encontramos en nuestra deriva, sino que es un tema muy presente en las entrevistas que hemos realizado: "Los derribos son muy violentos" (Informante JK.), "Vivimos con el miedo en el cuerpo" (Informante M. vecina del sector V), " y los escombros de las casas derribadas se quedan siempre ahí, para que cada vez que lo veas te recuerdes cómo puede terminar tu casa, (...) es muy duro eso" (Informante H.). Muchas son las asociaciones vecinales, ONG y colectivos que trabajan día a día junto a los vecinos para parar los derribos de viviendas, dando soporte legal y acompañamiento, así como atendiendo a los distintas problemas sociales que se presentan. Pero el problema, lejos de solucionarse, parece que se enreda en la esfera institucional. Esto se hace patente en los plenos de los ayuntamiento que hemos estudiado, donde el problema aparece "enquistado" por la falta de "voluntad política" y por "discordancias entre los distintos ayuntamientos implicados". Las negociaciones son muy complejas por la necesidad de llegar a un acuerdo de actuación integral en todo el territorio, pero que al mismo tiempo atienda a la diversidad de situaciones y necesidades que en él se dan. 


\section{Conclusiones}

A thing is what it is, only in and by reason of its limit. We cannot therefore regard the limit as only external to being which is then and there. It rather goes through and through the whole of such existence. Georg W.F. Hegel, Encyclopedia of Philosophical Science, 1817

La Cañada Real Galiana es un objeto múltiple y en disputa. La Cañada es territorio, la Cañada es la imagen que despliegan los medios de comunicación sobre ella, la Cañada también es un espacio vivido. Comprender la problemática que entraña este espacio requiere no sólo atender a diversas dimensiones o escalas (legal, morfológica, mediática o social), sino considerar la articulación de todas ellas en la conformación de imaginarios colectivos, planes urbanos o políticas. La Cañada Real, como hemos visto, se trata de un territorio de unas características muy particulares que han propiciado su ocupación a través de asentamientos informales. La falta de uso, su calidad como suelo demanial, el desarrollo de áreas urbanas contiguas y la demanda habitacional fueron factores que impulsaron el asentamiento espontáneo desde los años 60 . Pero no es hasta casi los años 2006-2007 cuando la Cañada Real no se introduce en las agendas políticas e irrumpe en la escena mediática.

La Cañada posee una huella en el territorio homogénea y constante de 70 metros de ancho (8$10 \mathrm{~m}$ de calle y $30 \mathrm{~m}$ a cada lado de fondo de parcela) durante los $15 \mathrm{~km}$ de recorrido entre Coslada y Getafe. Pero pese a tener una huella muy uniforme, hemos detectado morfo-tipologías bien diferenciadas que nos han llevado a distinguir 7 áreas morfo-tipológicas que responden a realidades muy distintas. Estas describen características muy dispares respecto a la ocupación de los solares, la distribución espacial, la diversidad en la intensidad de uso por parcela, la variación de características y calidades en la edificación y el contacto que genera con la ciudad próxima. La Cañada resulta por ello un ejemplo paradigmático de la gran complejidad que puede desplegarse sobre un patrón de asentamiento uniforme, pudiendo evolucionar de una manera desigual a lo largo del tiempo.

Esta diversidad choca con la aparente homogeneidad con las que se nos presenta La Cañada en los medios de comunicación. Los medios con frecuencia asimilan el conjunto de los $15 \mathrm{Km}$ de Cañada con el tramo Sur donde se sitúa el "mercado de la droga", presentándonos una imagen homogénea de la Cañada, como una realidad de miseria y delincuencia. Figuran un "espacio sin ley", "caótico", que debe de ser ordenado desde las instancias policiales y políticas. La criminalización de la "población flotante" no es solo un fenómeno propio de nuestro caso de estudio. Como muestra el trabajo de Mary Douglas, las personas que no encajan en las categorías de orden existentes tienden a ser vistas por la mayoría de las sociedades como personas "fuera de lugar" y una fuente de peligro y contaminación (Douglas 1966).

La Cañada además es un espacio fronterizo. Su estructura lineal extensa la convierte en una continua frontera con asentamientos consolidados contiguos como Coslada, los futuros desarrollos urbanos y Rivas-Vaciamadrid. Esta situación de continua negociación de los límites resulta muy problemática en algunas zonas donde no sólo se construye una frontera física, sino que también se construyen fronteras simbólicas que se encarnan a través de experiencias como vergüenza de los niños que acuden llenos de barro a las escuelas o miedo de los vecinos de los barrios contiguos. Como hemos comprobado con nuestro análisis, son múltiples los puntos de conflicto en los que se bloquean enlaces entre la Cañada y los nuevos proyectos urbanos; conflictos por las "pinchadas" de agua y electricidad y la posible contaminación de arroyos cercanos, que se materializan en 
bolardos de hormigón que impiden el paso, grafitis reivindicativos o bloqueo de tomas de agua. Estas situaciones estigmatizan a los vecinos del ámbito informal y dificultan la convivencia con la ciudad próxima.

El caso de La Cañada Real nos permite reflexionar sobre cómo se definen y actúan las políticas urbanas y, sobre todo, cómo estas se asientan en un sistema de legitimidad que dictamina qué es la ciudad y cuáles son sus límites. ¿No nos muestra este territorio precisamente ese límite entre dos mundos que se construyen por las dicotomías legales e ilegales, civilizadas e incivilizadas? ¿No constatan acaso los derribos de viviendas "ilegales" un modo de entender la ciudad y, por tanto, de aquello que puede construirse o derribarse legítimamente? No obstante ¿cuáles son los límites entre lo legal y lo legítimo? ¿Dónde termina lo ilegal y dónde comienza el derecho a una vivienda digna?

Los futuros de Cañada están aún abiertos, con la consolidación del asentamiento y la pasividad administrativa se perdió la oportunidad de mantener la Cañada como corredor verde de la ciudad. Del acuerdo entre las instituciones y los vecinos queda ahora la decisión de qué hacer con Cañada Real Galiana. Como sugiere esta investigación, para intervenir políticamente en este enclave es preciso tener en consideración diversas escalas y dimensiones que hacen de la Cañada un territorio complejo y heterogéneo. Si se busca dar respuestas que sean más sensibles al "problema de la Cañada" se deberá así poner en evidencia los imaginarios que los medios han generado en torno a este espacio, constatar la pluralidad de realidades urbanas que acoge y destacar la multitud de sentidos e intereses que en torno a él confluyen. Con esto queremos cuestionar los planteamientos que han querido ofrecer soluciones únicas tomando como argumento su patrón de asentamiento constante y su reducción a una realidad social chabolista y criminalizada. La realidad de la Cañada Real está lejos de ajustarse a un patrón único y por tanto aplicar sobre ella reglas unificadoras y homogeneizadoras presumiblemente sólo conseguirán la simplificación de este territorio, desposeyéndolo de su realidad compleja, al verse absorbido por los desarrollos urbanísticos que ya hay en marcha.

\section{Referencias}

\section{Referencias bibliográficas}

ALONSO, L. E. (1998) - La mirada cualitativa en sociología, Fundamentos, Madrid.

ASUÉ, L. (2008) - La ciudad invisible. Voces de la Cañada Real Galiana [vídeo DVD]. Madrid: Antropodocus, 52 $\min$.

CABRERIZO, C., RODRIGUEZ, I. (2014) - "Paisajes comunes de sociedades rotas: La Cañada de Madrid" en Territorios inconclusos y sociedades rotas. Trabajos de Campo del grupo de Geografía Urbana (AGE.)

CALABUIG, T., CÓNDOR, M.A. (1975) - La ciudad es nuestra. Madrid, 54 min. https://www.youtube.com/watch?v=RxpeFxtQXLs

CORSín, A. (2005) - "Changing Scales and the Scales of Change. Ethnography and Political Economy in Antofagasta, Chile”, Critique of Anthropology Vol 25(2) 157-176.

CRUZ ROJA ESPAÑOLA (2011) - “Informe de la Realidad sobre la Cañada Real”

DÍEZ, A., SÁNZ, A. Y ZAZO, A. (2011) - "Sendas de vida: la vida cotidiana en un enclave consolidado de la Cañada Real” en Vidas urbanas NS01, p. 117-125. 
EN LOS LÍMITES DE LA CIUDAD: El caso de la Cañada Real Galiana de Madrid

Territorios en Formación | 2017 | N11 | TRABAJOS FIN DE MÁSTER - Estudios Urbanos

DOUGLAS, M. (1966) - Purity and Danger: An Analysis of Concepts of Pollution and Taboo. Routledge, UK.

FARIÑA, J. (2009) - “Cañada Real Galiana, la vergüenza de Madrid” publicado en El Blog de José Fariña. (Visitado mayo 2016) http://elblogdefarina.blogspot.com.es/2009/09/canada-real-galiana-la-verguenza-de.html

FRANCHINI, M. (1988) - “Una ciudad lineal espontánea: La Cañada Real de Merinas” en Ciudad y Territorio n075, p.131-141.

FRANCO, O. (2005) - “Evolución reciente del fenómeno chabolista: el nuevo chabolismo madrileño” en La Ciudad y el Miedo, VII Coloquio de Geografía Urbana, Universitat de Girona, p.61-71.

KRISTEVA, J. (2006) - Poderes de la perversión: Ensayo sobre Louis-Ferdinand Céline. Ed. Siglo XXI.

MUMFORD, L. (1961) - The City in History: Its Origins, Its Transformations, and Its Prospects. NY.

SECRETARIADO GITANO (2011): Informe Social de Cañada Real Galiana. Programa de intervención.

STRATHERN, M. (1999) - "Puzzles of Scale", in Property, Substance and Effect: Anthropological Essays on Persons and Things. London and New Brunswick, NJ: Athlone Press.

TODO POR LA PRAXIS (2011): Plan Cañada.

KRISTEVA, J. (1980) Pouvoirs de I'horreur: essai sur l'abjection, Ed. Seuil

HEGEL, G. (1817) - Encyclopedia of Philosophical Science

WACQUANT, L., SLATER, T., PEREIRA, V. (2014) - “Estigmatización territorial en acción”, Revista INVI, 29(82), 219-240.

\section{Fuentes documentales}

El País (hemeroteca digital 2001-2015)

El Mundo (hemeroteca digital 2001-2015)

Plenos ayuntamientos (visitados en los meses de marzo-junio de 2016):

Ayuntamiento Coslada: http://coslada.es/semsys/ciudadanos/busqueda/termino

Ayuntamiento Rivas Vaciamadrid:

https://sede.rivasciudad.es/portal/sede/se_contenedor1.jsp?seccion=s_Idoc_d11_v1.jsp\&codbusqueda=20\&languag $\mathrm{e}=\mathrm{es} \& \operatorname{codRes} \mathrm{i}=1 \& \operatorname{codMenuPN}=3 \& \operatorname{codMenu}=16 \&$ layout=se_contenedor1.jsp\&layout=se_contenedor $1 . j \mathrm{sp}$

Ayuntamiento Madrid:

http://www.madrid.es/portales/munimadrid/es/Inicio/El-Ayuntamiento/El-Pleno/Actividad-del-Pleno-y-las-

Comisiones/Pleno/Sesiones-del-

Pleno?vgnextfmt=default\&vgnextoid=122481276d58c010VgnVCM100000d90ca8c0R 
